\title{
Effect of adjuvant radioactive iodine therapy on survival in rare oxyphilic subtype of thyroid cancer (Hürthle Cell Carcinoma)
}

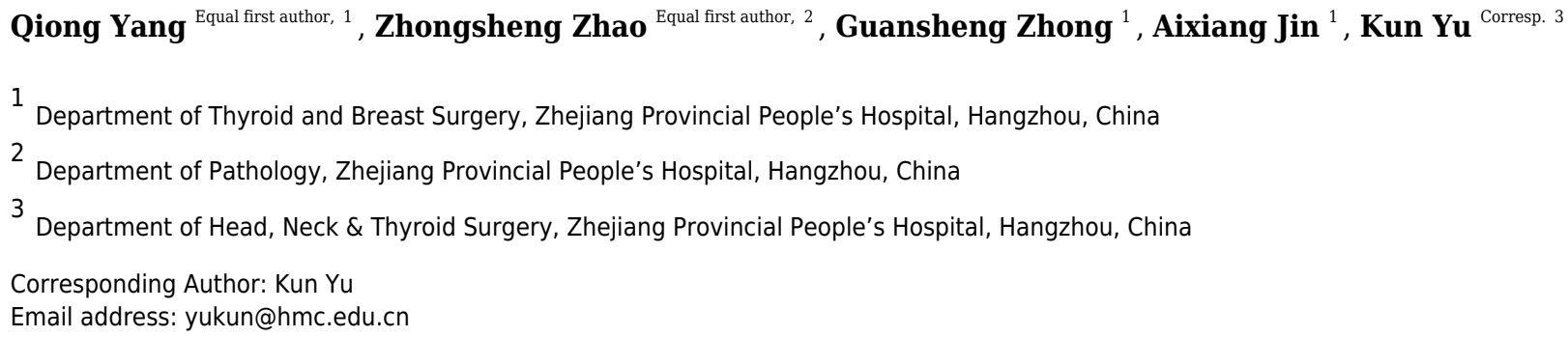

Purpose: Radioactive iodine (RAI) is widely used for adjuvant therapy after thyroidectomy, while its value for thyroid cancer has been controversial recently. The primary objectives of this study were to clarify the influence of Radioactive iodine (RAI) on the survival in rare oxyphilic subtype of thyroid cancer (Hürthle Cell Carcinoma, HCC). Methods: Patients diagnosed with oxyphilic thyroid carcinoma from 2004 to 2015 were extracted from the Surveillance, Epidemiology, and End Results Program database. The Kaplan-Meier method was used to compare overall survival (OS) and cancer-specific survival (CSS) among patients who had adjuvant RAI use or not. Univariate and multivariate Cox proportional hazard models were performed for survival analysis, and subsequently visualized by nomogram. Results: In all, 2799 patients were identified, of which 1529 patients had adjuvant RAI use while 1270 patients had not. Based on multivariate Cox analysis, the RAI therapy confers an improved OS for HCC patients (HR = $0.57,95 \% \mathrm{Cl}=0.44-0.72, \mathrm{P}<0.001)$, whereas it has no significant benefit in the survival analysis regarding CSS ( $\mathrm{HR}=0.79,95 \% \mathrm{Cl}=0.47-1.34, \mathrm{P}=0.382)$. In a subgroup analysis, the same survival benefit of RAI treatment on OS, but not CSS was observed among patients stratified by AJCC stage and tumor extension. Nevertheless, patients with regional lymph node metastasis benefited from RAI therapy both in OS and CSS (P< 0.001 , respectively). Furthermore, nomograms used for predicting long term survival of HCC patients exhibited a better prediction power for OS compared with traditional tumor, nodal and metastatic (TNM) stage made by American Joint Committee on Cancer (AJCC) (Cindex $=0.833$ of the nomogram model vs. 0.696 of the AJCC system). Conclusions: This study suggests that RAI therapy is significantly associated with improved OS in patients with Hürthle Cell Carcinoma. However, there were no association between treatment with radioiodine and CSS, possibly due to small number of deaths that were related to HCC. 


\section{Effect of adjuvant radioactive iodine therapy on survival in rare oxyphilic subtype of thyroid cancer (Hürthle Cell Carcinoma)}

Qiong Yang ${ }^{1, *}$, , Zhongsheng Zhao ${ }^{2, *}$, Guansheng Zhong ${ }^{1}$, Aixiang Jin ${ }^{1}, K^{\prime} u n \mathrm{Yu}^{3}$

1Department of Thyroid and Breast Surgery, Zhejiang Provincial People's Hospital, People's Hospital of Hangzhou Medical College, Hangzhou, Zhejiang 310014, P.R. China.

2Department of Pathology, Zhejiang Provincial People's Hospital, People's Hospital of Hangzhou Medical College, Hangzhou, Zhejiang 310014, P.R. China.

3Department of Head, Neck \& Thyroid Surgery, Zhejiang Provincial People's Hospital, People's Hospital of Hangzhou Medical College, Hangzhou, Zhejiang 310014, P.R. China.

*These authors contributed equally to this work. Corresponding Author:

Kun Yu

Email address: 342863441@qq.com

\section{Abstract}

Purpose: Radioactive iodine (RAI) is widely used for adjuvant therapy after thyroidectomy, while its value for thyroid cancer has been controversial recently. The primary objectives of this study were to clarify the influence of Radioactive iodine (RAI) on the survival in rare oxyphilic subtype of thyroid cancer (Hürthle Cell Carcinoma, HCC).

Methods: Patients diagnosed with oxyphilic thyroid carcinoma from 2004 to 2015 were extracted from the Surveillance, Epidemiology, and End Results Program database. The Kaplan-Meier method was used to compare overall survival (OS) and cancer-specific survival (CSS) among patients who had adjuvant RAI use or not. Univariate and multivariate Cox proportional hazard models were performed for survival analysis, and subsequently visualized by nomogram.

Results: In all, 2799 patients were identified, of which 1529 patients had adjuvant RAI use while 1270 patients had not. Based on multivariate Cox analysis, the RAI therapy confers an improved OS for HCC patients $(\mathrm{HR}=0.57,95 \% \mathrm{Cl}=0.44-0.72, \mathrm{P}<0.001)$, whereas it has no significant benefit in the survival analysis regarding CSS $(\mathrm{HR}=0.79,95 \% \mathrm{Cl}=0.47-1.34, \mathrm{P}=0.382)$. In a subgroup analysis, the same survival benefit of RAI treatment on OS, but not CSS was observed among patients stratified by AJCC stage and tumor extension. Nevertheless, patients with regional lymph node metastasis benefited from 
33 RAI therapy both in OS and CSS $(\mathrm{P}<0.001$, respectively). Furthermore, nomograms used for predicting 34 long term survival of HCC patients exhibited a better prediction power for OS compared with traditional 35 tumor, nodal and metastatic (TNM) stage made by American Joint Committee on Cancer (AJCC) (C-index $36=0.833$ of the nomogram model vs. 0.696 of the AJCC system).

37 Conclusions: This study suggests that RAI therapy is significantly associated with improved OS in patients with Hürthle Cell Carcinoma. However, there were no association between treatment with radioiodine and CSS, possibly due to small number of deaths that were related to HCC.

Keywords: Radioactive iodine, Hürthle Cell Carcinoma, SEER, Survival

\section{Introduction}

43 Oxyphilic thyroid carcinoma, also known as Hürthle Cell Carcinoma (HCC), is a rare and more aggressive 44 thyroid cancer developed from Hürthle Cell. Generally speaking, Hürthle Cell, or oxyphilic cells, are large polygonal cells with distinct borders in appearance originated from thyroid follicular epithelium (Ahmed et al. 2008). This rare type of thyroid cancer is comparatively less studied and accounts for $3-4 \%$ of all thyroid cancers (Hundahl et al. 2015). HCC, unlike its benign counterpart called Hürthle Cell adenoma, is identified as thyroid malignancy characterized with presence of capsular or vascular invasion, which cannot be determined by fine needle aspiration (FNA) (Mills et al. 2009). Moreover, the World Health Organization categorizes $\mathrm{HCC}$ as a variant of follicular carcinoma, hinting that $\mathrm{HCC}$ exhibits some characteristics similar to those of follicular carcinoma (Phitayakorn \& McHenry 2006). Specifically, according to the extent of vascular invasion, $\mathrm{HCC}$ can also be subdivided into minimally invasive type and extensive invasive type (Ganly et al. 2013). It has been well accepted that HCC have a high propensity for local invasion, lymphatic metastasis to the neck, or distant metastasis. As a consequence, patients suffered from HCC have a poor prognosis in comparison with other differentiated thyroid carcinoma due to its relatively higher recurrence rate and disease-specific mortality rate (Ghossein et al. 2006; Kushchayeva et al. 2004; Shaha et al. 1996).

Radioactive iodine (RAI) therapy is known widely to be effective in the treatment of thyroid cancer after thyroidectomy. However, as thyroid cancer treatment gradually tends to be conservative, the accurate survival benefit of postoperative RAl therapy remains disputable. Recently, there are increasing number of studies focusing on assessing the impact of postoperative RAI therapy on survival of thyroid 
62

63

64

65

66

67

68

69

70

71

72

73

74

75

76

77

78

79

80

81

82

83

84

85

86

87

88

89

cancer patient with different risk of recurrence identified by the American Thyroid Association (ATA) risk stratification system, and the results have varied (Ruel et al. 2015; Schvartz et al. 2012). However, to date, there is no reliable large population based research evaluating whether patients with HCC can benefit from postoperative RAI therapy. Hence, since HCC patients are considered to be refractory to RAI

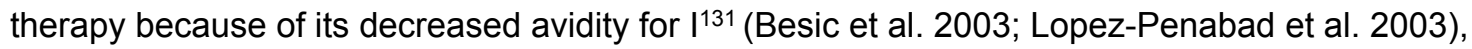
accurately evaluating the role of RAI therapy on the prognosis of $\mathrm{HCC}$ has become increasingly important.

In current study, a large population of HCC patients were identified in the Surveillance, Epidemiology, and End Results (SEER) database. Overall survival (OS) and cancer-specific survival (CSS) were comprehensively compared between patients who had been treated with RAI therapy and those who had not. The purpose of this study was to evaluate whether implementing RAl therapy could exert a clinical benefit in improving survival in patients with oxyphilic thyroid carcinoma.

\section{Materials \& Methods}

\section{Patient selection and variables extracted}

The SEER program is the largest publicly available cancer dataset containing information on cancer incidence, patient characteristics, and survival from various locations throughout the United States, which represents approximately $28 \%$ of the U.S. population (Wu et al. 2017). In our study, we signed a SEER research data agreement form to access the SEER data. Then, all the information of patients diagnosed with oxyphilic thyroid carcinoma (ICD-O-3 8290/3) from 2004 to 2015 were retrieved from 18 registries Custom Data (with additional treatment fields) using the SEER*Stat program ( $v$ 8.3.5). The inclusion criteria was as follows: (a) patients whose complete dates are available (i.e., date last contact $\geq$ date of diagnosis); (b) radiation recode was "None" or "Radioisotopes"; in addition, patients with unknown surgical type were excluded. Finally, a total of 2799 eligible patients were evaluated in this study. Since the SEER database is public and available worldwide, the informed consent is not required.

Variables including age, race, gender, marital status, surgery type, lymph nodes surgery type, chemotherapy recode, extension, AJCC TNM classification and tumor size, SEER cause-specific death classification, vital status and survival months were extracted and assessed. OS was defined as the date 
90 from diagnosis to death for any cause. CSS was defined as that the death were attributed directly to 91 oxyphilic thyroid carcinoma.

92

\section{Statistical analysis}

94 In this study, age was divided into $<45,45-64$ and $\geq 65$ years respectively. Marital status was coded into

952 categories: married and not married (single, widowed, separated and divorced). Since the detection rate of papillary thyroid microcarcinoma (PTMC) is increasing continually, partly due to rapid development of imaging diagnostic techniques, we redivided $\mathrm{HCC}$ into three subgroup ( $\leq 10 \mathrm{~mm}, 11-39 \mathrm{~mm}$ and $\geq 40 \mathrm{~mm}$ ) according to tumor size. Chi-square test was utilized to assess the baseline characteristics between RAI and no RAI group. Univariate and multivariate logistic regression analysis were used to identify factors associated with treatment of radioiodine. Kaplan-Meier plot and log-rank test were used to compare differences of OS and CSS between RAI and no-RAI group. Univariate and multivariate Cox proportional hazard model were performed for survival analysis in OS and CSS, and subsequently visualized by nomogram. All the statistical analyses were performed using SPSS 24.0 (Chicago, IL, USA). All the survival curve and nomogram were plotted using $R$ software version 3.4.4. A two-tailed $P<0.05$ was considered statistically significant.

106

\section{Results}

\section{Demographic characteristics of patients}

According to the inclusion criteria, a total of 2799 patients diagnosed with Hürthle Cell Carcinoma were identified from the SEER database, of which 1529 patients received adjuvant RAI therapy while 1270 patients did not receive RAI therapy. The baseline characteristics in each group are summarized in Table

112 1. As shown in Table 1, patients in the RAl group had higher proportion of 45-64-year-old age (45.3\% vs $11340.6 \%)$ and marriage (61.7\% vs $56.2 \%$ ) compared with no-RAl group. In addition, patients in RAl group 114 tended to have tumor being larger, later AJCC stage and more extent of extrathyroidal invasion than 115 those in the no-RAI group. Moreover, the RAI group had a higher percentage of total thyroidectomy $116(85.6 \%$ vs $57.6 \%)$ and regional lymph nodes dissection (34.7\% vs $22.9 \%)$ than no-RAI group. The 117 surprising thing is that there are $7 \%$ percentage of patients in no-RAI group who did not receive surgery 
118 treatment. Taking into consideration that HCC is only diagnosed in histologic analysis (Mills et al. 2009),

119 its diagnosis is most likely to come from the autopsy according to surgery codes of thyroid gland supplied 120 by SEER program.

121

122 Factors associated with use of radioactive iodine therapy

123 For the purpose of better understanding the clinicopathological factors associated with implementing of 124 RAI therapy, univariate and multivariate logistic regression analysis were performed (Table 2). In 125 univariate analysis, we demonstrated that age $\geq 65$, not married, and patients received partial 126 thyroidectomy or no surgery were less likely of receiving RAI therapy. Patients who underwent regional 127 lymph nodes dissection and had tumors with aggressive characteristics, such as larger tumor size and 128 more extrathyroidal involvement, were significantly associated with increased propensity of RAI use.

129 Moreover, the multivariate logistic analysis further suggested that patients who were younger age, larger 130 tumor size, received total thyroidectomy or regional lymph nodes dissection were more liable to be 131 treated with RAl therapy.

132

\section{Survival analysis of all population}

134 The median follow-up duration in this study was 5.2 years (mean, 5.4 years; range, 0 to 12 year). Of all 135 the 2799 patients finally evaluated, a total of 337 patients were dead at the time of last follow-up. 136 Importantly, 85 patients were dead directly from oxyphilic thyroid carcinoma. Subsequently, the Kaplan137 Meier plots was utilized to compare the overall survival (OS) and cancer specific survival (CSS) between 138 patients who had, or had not received RAl therapy. As shown in Fig. 1, patients received RAI therapy had 139 better OS $(P<0.05)$ than patients who had not received RAI therapy, whereas there is no statistical 140 significance for CSS between the two group $(P=0.11)$.

141 Cox proportional models were applied to assess the multiple factors related to survival. As shown in

142 Table 3, the univariate analysis displayed that older age, male, not married, advanced AJCC TNM stage, 143 larger tumor size ( $\geq 40 \mathrm{~mm}$ ) and extrathyroidal invasion were poor prognostic factors for OS of patients $144(H R>1, P<0.05)$, whereas treatments with RAI, total thyroidectomy and regional lymph nodes 145 dissection were proved to be protective factors for better $\mathrm{OS}(\mathrm{HR}<1, \mathrm{P}<0.05)$. To consider the possible 
146 bias between two group, all the aforementioned variables were then enlisted into the multivariate analysis

147 (Table 3). Notablely, RAI use still exerted as protective factor for improved OS $(\mathrm{HR}=0.57,95 \% \mathrm{Cl}=$

148 0.44-0.72, P < 0.05), compared with no-RAI group. Importantly, both univariate and multivariate Cox

149 regression analysis of CSS indicated that patients received RAI therapy has no significant survival

150 advantage over the patients without use of $\mathrm{RAI}(\mathrm{HR}=0.79,95 \% \mathrm{Cl}=0.44-1.34, \mathrm{P}>0.05)$. The detailed

151 Cox analysis for CSS were shown in Table 4. Taken together, these results suggested that patients with 152 oxyphilic thyroid carcinoma could benefit from RAI therapy in OS, but not in CSS.

153

\section{Nomograms for OS and CSS}

155 In order to predict the long term survival rate for patients with oxyphilic thyroid carcinoma, prognostic nomograms were depicted by eight prognostic factors, including age, sex, marital status, surgery type, RAI therapy, AJCC stage, lymph nodes metastatic status and distant metastatic status. Each factors mentioned above were proved to be significantly associated with OS in multivariate Cox proportional hazard regression model. As shown in Fig. 2A, each factors in the nomogram model could be ascribed a weighted point according to the point scale. The sum of the points could be used to predict the long term survival ( 3 year, 5 year and 10 year overall survival rate) according to the total points axis, wherein a higher score was deemed to have worse prognosis. Similarly, the nomogram employing aforementioned covariates was used to predict the cancer specific survival (Fig. 2B). Subsequently, the C-index for the multifactorial nomogram and the traditional AJCC TNM staging system were calculated and compared to evaluate the predictive accuracies. For OS and CSS, the c-index were 0.833 and 0.882 respectively, which were higher than that of the traditional AJCC staging system ( 0.696 and 0.867 respectively). These results, taken together, suggested that the nomograms built in this study were better than the traditional AJCC stage system at predicting prognosis.

169

\section{Impact of radioactive iodine on survival in subgroup}

171 In order to better understand the influence of RAI therapy on prognosis for the oxyphilic thyroid carcinoma 172 patients, we further studied the patients' OS and CSS in subgroup stratified by AJCC stage, extension 173 and lymph nodes metastatic status. Regarding AJCC stage, the Kaplan-Meier plots showed significant 
174 OS $(P<0.05)$ difference with RAI use in stages I-IV, whereas there is no significant difference in CSS

175 ( $P>0.05)$ (Fig. 3). In addition, similar results were shown in subgroup of patients who had oxyphilic

176 thyroid carcinoma with or without extrathyroidal invasion (Fig. 4). Furthermore, RAI therapy also acted a

177 significant survival benefit in OS for patients with no regional lymph node metastasis, whereas there was

178 no significant survival difference in CSS curves (Fig. 5). However, in the subgroups of patients who had

179 regional lymph node metastasis, RAI use has shown a significant survival advantage both in OS and CSS

180 (Fig. 5). Taken together, these data indicated that RAI therapy has significant survival benefits in OS for

181 the whole oxyphilic thyroid carcinoma patients, whereas there seems to be no association between RAI

182 treatment and CSS. Importantly, RAI therapy should be highly recommended for patients who had

183 regional lymph node metastasis because of the survival benefit both in OS and CSS.

184

185 Discussion

$186 \mathrm{HCC}$, a rare histological type among differentiated thyroid carcinoma, are diagnosed mainly based on

187 postoperative pathological examination, which is characterized with a finely granular eosinophilic

188 cytoplasm with increased number of mitochondria in it (Montone et al. 2008). HCC are classified to be

189 oxyphilic variants of follicular thyroid cancer (FTC), and inconsistent results were reported by previous

190 studies regarding the long term survival of HCCs compared with other differentiated thyroid carcinoma

191 (Haigh \& Urbach 2005). For example, some studies have proposed that HCC exhibits more aggressive

192 and poor prognosis than conventional papillary carcinoma and follicular carcinoma, which should be

193 categorized as distinct tumor (Azadian et al. 1995; Bishop et al. 2012; Kushchayeva et al. 2004;

194 Kushchayeva et al. 2008). However, Haigh et al have reported that HCC patients had similar prognosis

195 compared to their non-HCC counterparts after matching important prognostic variables including age and

196 tumor stage, and suggested that patients with HCCs should be treated the same as non-HCC patients

197 with equivalent stage (Haigh \& Urbach 2005). Generally, a total thyroidectomy is recommended for HCCs

198 due to its aggressive behavior and also due in part to an increased rate of locoregional recurrence

199 (Bishop et al. 2012; Haigh \& Urbach 2005; Petric et al. 2014).

PeerJ reviewing PDF | (2019:04:36648:2:0:NEW 9 Jul 2019) 
200

201

202

203

204

205

206

207

208

209

210

211

212

213

214

215

216

217

218

219

220

221

222

223

224

225

226

227

Recently, RAI therapy is widely used for adjuvant treatment after total thyroidectomy for the purpose of ablating unresectable residual lesions and meanwhile predicting tumor persistence or recurrence by monitoring the thyroglobulin ( $\mathrm{Tg}$ ) level and/or implementing of RAI whole-body scan (Besic et al. 2003; Foote et al. 2003). However, the recommendations regarding the RAI use for HCC differs across the American Thyroid Association (ATA) and the NCCN guidelines(Haugen et al. 2016; Jillard et al. 2016). It remains contradictory whether the use of adjuvant RAI therapy might improve survival of patients suffered from HCCs, because it is generally believed that fewer than $10 \%$ of HCCs take up radioiodine (Arganini et al. 1986; Kushchayeva et al. 2004; Stojadinovic et al. 2002). To the best of our knowledge, there is no large clinical trials that evaluated the efficacy or survival benefit of RAI use for HCC except for a few small retrospective studies(Kushchayeva et al. 2004; Lopez-Penabad et al. 2003), largely because of its relative rarity. Therefore, multi-institutional trials should be pursued to standardize and reinforce the published management guidelines.

In this study, we retrospectively analyzed the difference between two cohort of HCC patients received RAI treatment or not, based on a large population extracted from SEER database. We observed that patients who received RAI therapy tend to have tumors with later stage and receive more aggressive treatment like total thyroidectomy or regional lymph nodes dissection. Intriguingly, a higher proportion of patients who had married were observed in the RAI group. We also assessed the clinicopathological variables significantly associated with use of RAI therapy using the univariate and multivariate logistic regression analysis. Our result revealed that patients with younger age, larger tumor size and received total thyroidectomy or regional lymph nodes dissection were independent factors associated with use of RAI.

In order to evaluate whether adjuvant RAI therapy had an improved survival for HCCs patient, we performed survival analysis using Kaplan-Meier plots and Cox analysis. We demonstrated that the RAI therapy confers an improved OS for HCCs patients after taking into consideration of multiple clinicopathological variables in multivariate Cox's regression analysis. Interestingly, both univariate and multivariate Cox survival analysis showed that patients who have married had better OS than unmarried one. We hypothesized that either financial or psychological support from family could be an important contributing factors associated with good prognosis. Nevertheless, in the survival analysis regarding CSS, 
228 the result showed that no survival benefit of RAI therapy was apparent both in univariate and multivariate 229 Cox proportional hazard regression model. However, of the totally 2799 patients, only 85 cases were 230 dead directly from Hürthle Cell Carcinoma, hence we can't conclude that HCCs patients didn't achieve 231 survival benefits from implement of RAI therapy due to the insufficient statistical power of incidents.

232 Further validation cohort or large prospective studies containing more patients death attributed directly to 233 HCCs are needed in the future.

234 In our study, specific nomogram prediction models for OS and CSS were developed separately for 235 patients with Hürthle Cell Carcinoma. Based on the results from multivariate Cox regression analysis, we utilized eight factors significantly associated with overall survival to predict long term survival in the nomogram model, in which a higher score point suggested worse prognosis. Subsequently, we evaluated the predictive accuracy of the nomogram model and compared to that of the traditional AJCC staging system though calculating the C-index. The results indicated that the nomogram model regarding OS showed a better prognosis power than traditional AJCC TNM staging system (C-index $=0.833$ of the nomogram model vs. 0.696 of the AJCC stage system). So, our nomogram system appears to be a better alternative to predict long term survival in patients suffered from Hürthle Cell Carcinoma. In order to evaluate the influence of RAI treatment on prognosis of HCC patients, we further stratified

244 all the population for further survival analysis according to AJCC stage, status of regional lymph nodes 245 and extent of extrathyroidal invasion. In consequence, we came to the same conclusion in subgroup 246 survival analysis for patients both in I-II and III-IV population, and patients with or without extrathyroidal 247 invasion. Notably, the subgroup analysis for patients suffered regional lymph node metastasis indicated that RAI therapy exerted survival benefits both in OS and CSS. As lymph node metastases are reportedly more common in patients with HCC (Evans \& Vassilopoulou-Sellin 1998), our result highlighted the vital role of RAI therapy for HCC patients with regional lymph node metastasis Inevitably, the current study has some limitations. Firstly, the SEER database lacked information regarding cancer recurrence, which limited us to assess the impact of RAI treatment on locoregional recurrence. Secondly, the information, including dosage of RAI, extranodal extension and size of the largest metastatic lymph node were not available from SEER database, which were reported to have 
256

257

258

259

260

261

262

263

264

265

266

267

268

269

270

271

272

273

274

275

276

277

278

279

280

281

282

283

284

285

286

287

288

289

290

291

292

293

294

295

296

known thyroid cancer oncogenes, such as $B R A F$, were not available or adjusted in our study.

Furthermore, the number of events occurred in CSS analysis were too small and thus compromised the statistical power.

\section{Conclusions}

In summary, this study suggests that RAI therapy was significantly associated with improved OS in patients with Hürthle Cell Carcinoma. However, there were no association between treatment with radioiodine and CSS, possibly due to small number of deaths that were related to HCC.

\section{Acknowledgements}

This study is based on the SEER database.

\section{References}

Ahmed M, Bin Yousef H, Greer W, Faraz H, Al Sobhi S, Al Zahrani A, Raef H, Al Ghamdi A, Al Kadhi Y, and Al Dayel F. 2008. Hurthle cell neoplasm of the thyroid gland. ANZ J Surg 78:139-143. 10.1111/j.1445-2197.2007.04389.

Arganini M, Behar R, Wu TC, Straus F, 2nd, McCormick M, DeGroot LJ, and Kaplan EL. 1986. Hurthle cell tumors: a twenty-five-year experience. Surgery 100:1108-1115.

Azadian A, Rosen IB, Walfish PG, and Asa SL. 1995. Management considerations in Hurthle cell carcinoma. Surgery 118:711-714; discussion 714-715.

Besic N, Vidergar-Kralj B, Frkovic-Grazio S, Movrin-Stanovnik T, and Auersperg M. 2003. The role of radioactive iodine in the treatment of Hurthle cell carcinoma of the thyroid. Thyroid 13:577-584. 10.1089/105072503322238845.

Bishop JA, Gaosong W, Tufano RP, and Westra WH. 2012. Histological patterns of locoregional recurrence in Hürthle cell carcinoma of the thyroid gland. Thyroid 22:690-694.

Evans HL, and Vassilopoulou-Sellin R, . 1998. Follicular and Hurthle cell carcinomas of the thyroid: a comparative study. American Journal of Surgical Pathology 22:1512-1520.

Foote RL, Brown PD, Garces YI, Mclver B, and Kasperbauer JL. 2003. Is there a role for radiation therapy in the management of Hurthle cell carcinoma? Int $J$ Radiat Oncol Biol Phys 56:1067-1072.

Ganly I, Ricarte Filho J, Eng S, Ghossein R, Morris LG, Liang Y, Socci N, Kannan K, Mo Q, Fagin JA, and Chan TA. 2013. Genomic dissection of Hurthle cell carcinoma reveals a unique class of thyroid malignancy. J Clin Endocrinol Metab 98:E962-972. 10.1210/jc.2012-3539

Ghossein RA, Hiltzik DH, Carlson DL, Patel S, Shaha A, Shah JP, Tuttle RM, and Singh B. 2006. Prognostic factors of recurrence in encapsulated Hurthle cell carcinoma of the thyroid gland: a clinicopathologic study of 50 cases. Cancer 106:1669-1676. 10.1002/cncr.21825.

Haigh PI, and Urbach DR. 2005. The treatment and prognosis of Hurthle cell follicular thyroid carcinoma compared with its non-Hurthle cell counterpart. Surgery 138:1152-1157; discussion 1157-1158. 10.1016/j.surg.2005.08.034.

Haugen BR, Alexander EK, Bible KC, Doherty GM, Mandel SJ, Nikiforov YE, Pacini F, Randolph

PeerJ reviewing PDF | (2019:04:36648:2:0:NEW 9 Jul 2019) 
297

298

299

300

301

302

303

304

305

306

307

308

309

310

311

312

313

314

315

316

317

318

319

320

321

322

323

324

325

326

327

328

329

330

331

332

333

334

335

336

337

338

339

340

341

342

343

344

345

346

347

GW, Sawka AM, Schlumberger M, Schuff KG, Sherman SI, Sosa JA, Steward DL, Tuttle RM, and Wartofsky L. 2016. 2015 American Thyroid Association Management Guidelines for Adult Patients with Thyroid Nodules and Differentiated Thyroid Cancer: The American Thyroid Association Guidelines Task Force on Thyroid Nodules and Differentiated Thyroid Cancer. Thyroid 26:1-133. 10.1089/thy.2015.0020.

HundahI SA, Fleming ID, Fremgen AM, and Menck HR. 2015. A National Cancer Data Base report on 53,856 cases of thyroid carcinoma treated in the U.S., 1985-1995 [see commetns]. Cancer 83:2638-2648.

Jillard CL, Youngwirth L, Scheri RP, Roman S, and Sosa JA. 2016. Radioactive lodine Treatment Is Associated with Improved Survival for Patients with Hurthle Cell Carcinoma. Thyroid 26:959-964. 10.1089/thy.2016.0246.

Kushchayeva Y, Duh QY, Kebebew E, and Clark OH. 2004. Prognostic indications for Hurthle cell cancer. World J Surg 28:1266-1270. 10.1007/s00268-004-7602-2

Kushchayeva Y, Duh QY, Kebebew E, D'Avanzo A, and Clark OH. 2008. Comparison of clinical characteristics at diagnosis and during follow-up in 118 patients with Hurthle cell or follicular thyroid cancer. Am J Surg 195:457-462.

Lopez-Penabad L, Chiu AC, Hoff AO, Schultz P, Gaztambide S, Ordonez NG, and Sherman SI. 2003. Prognostic factors in patients with Hurthle cell neoplasms of the thyroid. Cancer 97:1186-1194. 10.1002/cncr.11176.

Mills SC, Haq M, Smellie WJ, and Harmer C. 2009. Hurthle cell carcinoma of the thyroid: Retrospective review of 62 patients treated at the Royal Marsden Hospital between 1946 and 2003. Eur J Surg Oncol 35:230-234. 10.1016/j.ejso.2008.06.007.

Montone KT, Baloch ZW, and LiVolsi VA. 2008. The thyroid Hurthle (oncocytic) cell and its associated pathologic conditions: a surgical pathology and cytopathology review. Arch Pathol Lab Med 132:1241-1250. 10.1043/1543-2165(2008)132[1241:tthoca]2.0.co;2.

Petric R, Gazic B, and Besic N. 2014. Prognostic factors for disease-specific survival in 108 patients with Hurthle cell thyroid carcinoma: a single-institution experience. BMC Cancer 14:777. 10.1186/1471-2407-14-777.

Phitayakorn R, and McHenry CR. 2006. Follicular and Hurthle cell carcinoma of the thyroid gland. Surg Oncol Clin N Am 15:603-623, ix-x. 10.1016/j.soc.2006.05.011.

Randolph GW, Duh QY, Heller KS, LiVolsi VA, Mandel SJ, Steward DL, Tufano RP, and Tuttle RM. 2012. The prognostic significance of nodal metastases from papillary thyroid carcinoma can be stratified based on the size and number of metastatic lymph nodes, as well as the presence of extranodal extension. Thyroid 22:1144-1152. 10.1089/thy.2012.0043.

Ruel E, Thomas S, Dinan M, Perkins JM, Roman SA, and Sosa JA. 2015. Adjuvant radioactive iodine therapy is associated with improved survival for patients with intermediate-risk papillary thyroid cancer. J Clin Endocrinol Metab 100:1529-1536. 10.1210/jc.2014-4332.

Schvartz C, Bonnetain F, Dabakuyo S, Gauthier M, Cueff A, Fieffe S, Pochart JM, Cochet I, Crevisy E, Dalac A, Papathanassiou D, and Toubeau M. 2012. Impact on overall survival of radioactive iodine in low-risk differentiated thyroid cancer patients. J Clin Endocrinol Metab 97:1526-1535. 10.1210/jc.2011-2512.

Shaha AR, Shah JP, and Loree TR. 1996. Patterns of nodal and distant metastasis based on histologic varieties in differentiated carcinoma of the thyroid. Am J Surg 172:692-694.

Stojadinovic A, Hoos A, Ghossein RA, Urist MJ, Leung DH, Spiro RH, Shah JP, Brennan MF, Singh B, and Shaha AR. 2002. Hurthle cell carcinoma: a 60-year experience. Ann Surg Oncol 9:197-203.

Wu MH, Shen WT, Gosnell J, and Duh QY. 2015. Prognostic significance of extranodal extension of regional lymph node metastasis in papillary thyroid cancer. Head Neck 37:1336-1343. 10.1002/hed.23747.

Wu W, He X, Andayani D, Yang L, Ye J, Li Y, Chen Y, and Li L. 2017. Pattern of distant

PeerJ reviewing PDF | (2019:04:36648:2:0:NEW 9 Jul 2019) 


\section{Table 1 (on next page)}

Baseline characteristics of HCC patients in this study. 
1

\begin{tabular}{|c|c|c|c|c|}
\hline \multirow[t]{2}{*}{ Characteristics } & Total, n (\%) & No RAI, n (\%) & RAI, n (\%) & *P value \\
\hline & $\mathrm{N}=2799$ & $\mathrm{~N}=1270$ & \multicolumn{2}{|l|}{$\mathrm{N}=1529$} \\
\hline \multicolumn{5}{|l|}{ Age } \\
\hline$<45$ & $587 \quad(21)$ & $240(18.9)$ & $347(22.7)$ & $<0.001$ \\
\hline 45-64 & $1207 \quad(43.1)$ & $515(40.6)$ & $692(45.3)$ & \\
\hline$\geq 65$ & $1005 \quad(35.9)$ & $515(40.6)$ & $490(32)$ & \\
\hline \multicolumn{5}{|l|}{ Race } \\
\hline Black & $240(8.6)$ & $107(8.4)$ & $133(8.7)$ & 0.678 \\
\hline White & $2341(83.6)$ & $1058(83.3)$ & $1283(83.9)$ & \\
\hline Other & $218(7.8)$ & $105(8.3)$ & $113(7.4)$ & \\
\hline \multicolumn{5}{|l|}{ Sex } \\
\hline Female & $1938(69.2)$ & $902(71)$ & $1036(67.8)$ & 0.062 \\
\hline Male & $861(30.8)$ & $368(29)$ & $493(32.2)$ & \\
\hline \multicolumn{5}{|l|}{ Marital status } \\
\hline Married & $1658(59.2)$ & $714(56.2)$ & $944(61.7)$ & 0.001 \\
\hline Not married & $990(35.4)$ & $468(36.9)$ & $522(34.1)$ & \\
\hline Unknown & $151(5.4)$ & $88(6.9)$ & $63(4.1)$ & \\
\hline \multicolumn{5}{|l|}{ Surgery } \\
\hline Total thyroidectomy & $2040(72.9)$ & $731(57.6)$ & $1309(85.6)$ & $<0.001$ \\
\hline Partial thyroidectomy & $668(23.9)$ & $450(35.4)$ & $218(14.3)$ & \\
\hline No surgery & $91(3.3)$ & $89(7.0)$ & $2(0.1)$ & \\
\hline \multicolumn{5}{|l|}{ Lymph nodes surgery } \\
\hline No & $1903(68.0)$ & 938 (73.9) & $965(63.1)$ & $<0.001$ \\
\hline Regional lymph nodes dissection & $822(29.4)$ & $291(22.9)$ & $531(34.7)$ & \\
\hline Unknown & $74(2.6)$ & $41(3.2)$ & $33(2.2)$ & \\
\hline \multicolumn{5}{|l|}{ Chemotherapy } \\
\hline No & $2784(99.5)$ & $1259(99.1)$ & 1525 (99.7) & 0.029 \\
\hline Chemotherapy & $15(0.5)$ & $11(0.9)$ & $4(0.3)$ & \\
\hline \multicolumn{5}{|l|}{ Seer_stage } \\
\hline Localized & $2347(83.9)$ & $1049(82.6)$ & $1298(84.9)$ & $<0.001$ \\
\hline Regional & $305(10.9)$ & $130(10.2)$ & $175(11.4)$ & \\
\hline Distant & $98(3.5)$ & $50(3.9)$ & $48(3.1)$ & \\
\hline Unknown & $49(1.8)$ & $41(3.2)$ & $8(0.5)$ & \\
\hline \multicolumn{5}{|l|}{ AJCC_stage } \\
\hline $\mathbf{I}$ & $1077(38.5)$ & $486(38.3)$ & $591(38.7)$ & $<0.001$ \\
\hline II & $686(24.5)$ & $304(23.9)$ & $382(25.0)$ & \\
\hline III & $687(24.5)$ & $276(21.7)$ & $411(26.9)$ & \\
\hline IV & $163(5.8)$ & $79(6.2)$ & $84(5.5)$ & \\
\hline Unknown & $186(6.6)$ & $125(9.8)$ & $61(4.0)$ & \\
\hline
\end{tabular}

T 


\begin{tabular}{|c|c|c|c|c|}
\hline T1 & $676(24.2)$ & $338(26.6)$ & $338(22.1)$ & $<0.001$ \\
\hline $\mathbf{T 2}$ & $962(34.4)$ & $415(32.7)$ & $547(35.8)$ & \\
\hline T3 & $908(32.4)$ & $359(28.3)$ & $549(35.9)$ & \\
\hline T4 & $95(3.4)$ & $45(3.5)$ & $50(3.3)$ & \\
\hline TX & $158(5.6)$ & $113(8.9)$ & $45(2.9)$ & \\
\hline \multicolumn{5}{|l|}{$\mathbf{N}$} \\
\hline No & $2540(90.7)$ & $1125(88.6)$ & $1415(92.5)$ & $<0.001$ \\
\hline N1 & $141(5.0)$ & $60(4.7)$ & $81(5.3)$ & \\
\hline NX & $118(4.2)$ & $85(6.7)$ & $33(2.2)$ & \\
\hline \multicolumn{5}{|l|}{$\mathbf{M}$} \\
\hline M0 & $2657(94.9)$ & $1182(93.1)$ & $1475(96.5)$ & $<0.001$ \\
\hline M1 & $67(2.4)$ & $30(2.4)$ & $37(2.4)$ & \\
\hline MX & $75(2.7)$ & $58(4.6)$ & $17(1.1)$ & \\
\hline \multicolumn{5}{|l|}{ Tumor_size (mm) } \\
\hline$\leq 10$ & $184(6.6)$ & $130(10.2)$ & $54(3.5)$ & $<0.001$ \\
\hline 11-39 & $1580(56.4)$ & $676(53.2)$ & $904(59.1)$ & \\
\hline$\geq 40$ & $859(30.7)$ & $341(26.9)$ & $518(33.9)$ & \\
\hline Unknown & $176(6.3)$ & $123(9.7)$ & $53(3.5)$ & \\
\hline \multicolumn{5}{|l|}{ Extension } \\
\hline Intrathyroidal & $1499(53.6)$ & $699(55.0)$ & $800(52.3)$ & $<0.001$ \\
\hline Extrathyroidal & $1131(40.4)$ & $463(36.5)$ & $668(43.7)$ & \\
\hline Unknown & $169(6.0)$ & $108(8.5)$ & $61(4.0)$ & \\
\hline
\end{tabular}

* P valuzs were calculated by Chi-square test.

3

4

5 
Table 2 (on next page)

Factors associated with RAI use. 


\begin{tabular}{|c|c|c|c|c|}
\hline \multirow[b]{2}{*}{ Variables } & \multicolumn{2}{|c|}{ Univariate logistic model } & \multicolumn{2}{|c|}{ Multivariate logistic model } \\
\hline & OR $(95 \% \mathrm{CI})$ & $P$ value & OR $(95 \% \mathrm{CI})$ & $P$ value \\
\hline \multicolumn{5}{|l|}{ Age } \\
\hline$<45$ & Reference & & Reference & \\
\hline 45-64 & $0.93(0.76-1.14)$ & 0.47 & $0.95(0.76-1.18)$ & 0.62 \\
\hline$\geq 65$ & $0.66(0.54-0.81)$ & $<0.001$ & $0.71(0.56-0.88)$ & 0.002 \\
\hline \multicolumn{5}{|l|}{ Sex } \\
\hline Female & Reference & & Reference & \\
\hline Male & $1.17(0.99-1.37)$ & 0.062 & $1.13(0.94-1.36)$ & 0.197 \\
\hline \multicolumn{5}{|l|}{ Marital status } \\
\hline Married & Reference & & Reference & \\
\hline Not married & $0.84(0.72-0.99)$ & 0.035 & $0.92(0.78-1.10)$ & 0.38 \\
\hline \multicolumn{5}{|l|}{ Surgery } \\
\hline Total thyroidectomy & Reference & & Reference & \\
\hline Partial thyroidectomy & $0.27(0.23-0.33)$ & $<0.001$ & $0.28(0.23-0.33)$ & $<0.001$ \\
\hline No surgery & $0.01(0.003-0.05)$ & $<0.001$ & $0.02(0.005-0.09)$ & $<0.001$ \\
\hline \multicolumn{5}{|l|}{ Lymph nodes surgery } \\
\hline No & Reference & & Reference & \\
\hline Regional lymph nodes dissection & $1.77(1.50-2.10)$ & $<0.001$ & $1.50(1.25-1.80)$ & $<0.001$ \\
\hline \multicolumn{5}{|l|}{ Tumor size (mm) } \\
\hline$\leq 10$ & Reference & & Reference & \\
\hline 11-39 & $3.22(2.31-4.49)$ & $<0.001$ & $3.50(2.46-4.97)$ & $<0.001$ \\
\hline$\geq 40$ & $3.66(2.59-5.17)$ & $<0.001$ & $4.16(2.86-6.04)$ & $<0.001$ \\
\hline \multicolumn{5}{|l|}{ Lymph nodes metastases } \\
\hline No & Reference & & & \\
\hline Yes & $1.073(0.76-1.51)$ & 0.686 & & \\
\hline \multicolumn{5}{|l|}{ Distant metastases } \\
\hline No & Reference & & & \\
\hline Yes & $0.99(0.61-1.61)$ & 0.61 & & \\
\hline \multicolumn{5}{|l|}{ Extension } \\
\hline Intrathyroidal & Reference & & Reference & \\
\hline Extrathyroidal & $1.26(1.08-1.47)$ & 0.004 & $1.14(0.96-1.35)$ & 0.086 \\
\hline
\end{tabular}

OR, odds ratio. 


\section{Table 3 (on next page)}

Cox proportional hazards regression model analysis of overall survival (OS). 


\begin{tabular}{|c|c|c|c|c|}
\hline \multirow[b]{2}{*}{ Characteristics } & \multicolumn{2}{|l|}{ Univariate Cox } & \multicolumn{2}{|l|}{ Multivariate Cox } \\
\hline & $\operatorname{HR}(95 \% \mathrm{CI})$ & $P$ value & HR $(95 \%$ CI $)$ & $P$ value \\
\hline \multicolumn{5}{|l|}{ Age } \\
\hline$<45$ & Reference & & Reference & \\
\hline $45-64$ & $3.88(1.94-7.76)$ & $<0.001$ & $3.08(1.43-6.63)$ & 0.004 \\
\hline$\geq 65$ & $21.1(10.8-40.9)$ & $<0.001$ & $13.3(6.32-27.8)$ & $<0.001$ \\
\hline \multicolumn{5}{|l|}{ Sex } \\
\hline Female & Reference & & Reference & \\
\hline Male & $1.68(1.35-2.09)$ & $<0.001$ & $1.43(1.14-1.81)$ & 0.002 \\
\hline \multicolumn{5}{|l|}{ Marital status } \\
\hline Married & Reference & & Reference & \\
\hline Not married & $1.73(1.39-2.15)$ & $<0.001$ & $1.73(1.37-2.18)$ & $<0.001$ \\
\hline \multicolumn{5}{|l|}{ Surgery } \\
\hline Total thyroidectomy & Reference & & Reference & \\
\hline Partial thyroidectomy & $1.40(1.10-1.79)$ & 0.007 & $1.14(0.88-1.48)$ & 0.312 \\
\hline No surgery & $7.46(5.29-10.5)$ & $<0.001$ & $4.03(2.43-6.70)$ & $<0.001$ \\
\hline \multicolumn{5}{|l|}{ Lymph nodes surgery } \\
\hline No & Reference & & Reference & \\
\hline Regional lymph nodes dissection & $0.71(0.55-0.92)$ & 0.009 & $0.82(0.60-1.11)$ & 0.201 \\
\hline \multicolumn{5}{|l|}{ Radiation } \\
\hline No RAI & Reference & & Reference & \\
\hline RAI & $0.47(0.37-0.58)$ & $<0.001$ & $0.57(0.44-0.72)$ & $<0.001$ \\
\hline \multicolumn{5}{|l|}{ AJCC stage } \\
\hline $\mathbf{I}$ & Reference & & Reference & \\
\hline II & $2.62(1.84-3.75)$ & $<0.001$ & $1.32(0.88-1.98)$ & 0.178 \\
\hline III & $3.69(2.63-5.18)$ & $<0.001$ & $1.07(0.64-1.80)$ & 0.794 \\
\hline IV & $14.9(10.4-21.3)$ & $<0.001$ & $2.77(1.52-5.05)$ & 0.001 \\
\hline \multicolumn{5}{|l|}{ Tumor size (mm) } \\
\hline$\leq 10$ & Reference & & Reference & \\
\hline 11-39 & $1.26(0.72-2.23)$ & 0.420 & $1.11(0.60-2.07)$ & 0.738 \\
\hline$\geq 40$ & $2.30(1.30-4.06)$ & 0.004 & $1.58(0.79-3.14)$ & 0.193 \\
\hline \multicolumn{5}{|l|}{ Lymph nodes metastases } \\
\hline No & Reference & & Reference & \\
\hline Yes & $3.46(2.47-4.84)$ & $<0.001$ & $1.65(1.02-2.69)$ & 0.043 \\
\hline \multicolumn{5}{|l|}{ Distant metastases } \\
\hline No & Reference & & Reference & \\
\hline Yes & $10.39(7.39-14.6)$ & $<0.001$ & $2.31(1.38-3.86)$ & 0.002 \\
\hline \multicolumn{5}{|l|}{ Extension } \\
\hline Intrathyroidal & Reference & & Reference & \\
\hline Extrathyroidal & $1.44(1.15-1.80)$ & 0.002 & $1.10(0.86-1.40)$ & 0.442 \\
\hline
\end{tabular}




\section{Table 4 (on next page)}

Cox proportional hazards regression model analysis of Cancer-specific survival (CSS). 


\begin{tabular}{|c|c|c|c|c|}
\hline \multirow[b]{2}{*}{ Characteristics } & \multicolumn{2}{|l|}{ Univariate Cox } & \multicolumn{2}{|l|}{ Multivariate Cox } \\
\hline & OR $(95 \% \mathrm{CI})$ & $P$ value & OR $(95 \% \mathrm{CI})$ & $P$ value \\
\hline \multicolumn{5}{|l|}{ Age } \\
\hline$<45$ & Reference & & Reference & \\
\hline 45-64 & $2.64(0.91-7.69)$ & 0.075 & $0.36(0.06-1.99)$ & 0.239 \\
\hline$\geq 65$ & $10.7(3.88-29.4)$ & $<0.001$ & $0.91(0.17-4.99)$ & 0.915 \\
\hline \multicolumn{5}{|l|}{ Sex } \\
\hline Female & Reference & & Reference & \\
\hline Male & $1.96(1.27-3.00)$ & 0.002 & $1.35(0.84-2.17)$ & 0.217 \\
\hline \multicolumn{5}{|l|}{ Marital status } \\
\hline Married & Reference & & Reference & \\
\hline Not married & $1.48(0.96-2.27)$ & 0.074 & $1.50(0.93-2.41)$ & 0.098 \\
\hline \multicolumn{5}{|l|}{ Surgery } \\
\hline Total thyroidectomy & Reference & & Reference & \\
\hline Partial thyroidectomy & $0.97(0.56-1.67)$ & 0.911 & $1.14(0.63-2.06)$ & 0.671 \\
\hline No surgery & $9.48(5.25-17.1)$ & $<0.001$ & $2.88(1.12-7.41)$ & 0.028 \\
\hline \multicolumn{5}{|l|}{ Lymph nodes surgery } \\
\hline No & Reference & & Reference & \\
\hline Regional lymph nodes dissection & $1.44(0.91-2.28)$ & 0.119 & $0.99(0.54-1.84)$ & 0.98 \\
\hline \multicolumn{5}{|l|}{ Radiation } \\
\hline No RAI & Reference & & Reference & \\
\hline RAI & $0.71(0.46-1.09)$ & 0.113 & $0.79(0.47-1.34)$ & 0.382 \\
\hline \multicolumn{5}{|l|}{ AJCC stage } \\
\hline $\mathbf{I}$ & Reference & & Reference & \\
\hline II & $2.44(0.69-8.65)$ & 0.167 & $4.48(0.73-27.6)$ & 0.106 \\
\hline III & $9.96(3.44-28.8)$ & $<0.001$ & $7.10(1.21-41.6)$ & 0.030 \\
\hline IV & $109.3(39.3-303.5)$ & $<0.001$ & $37.4(6.11-228.7)$ & $<0.001$ \\
\hline \multicolumn{5}{|l|}{ Tumor size (mm) } \\
\hline$\leq 10$ & Reference & & Reference & \\
\hline 11-39 & $1.21(0.29-5.15)$ & 0.796 & $1.00(0.19-5.27)$ & 0.999 \\
\hline$\geq \mathbf{4 0}$ & $5.46(1.33-22.5)$ & 0.019 & $2.20(0.44-11.0)$ & 0.339 \\
\hline \multicolumn{5}{|l|}{ Lymph nodes metastases } \\
\hline No & Reference & & Reference & \\
\hline Yes & $11.3(6.91-18.3)$ & $<0.001$ & $1.87(0.90-3.88)$ & 0.092 \\
\hline \multicolumn{5}{|l|}{ Distant metastases } \\
\hline No & Reference & & Reference & \\
\hline Yes & $36.6(22.8-58.6)$ & $<0.001$ & $3.25(1.66-6.34)$ & 0.001 \\
\hline \multicolumn{5}{|l|}{ Extension } \\
\hline Intrathyroidal & Reference & & Reference & \\
\hline Extrathyroidal & $3.95(2.35-6.66)$ & $<0.001$ & $1.67(0.95-2.95)$ & 0.074 \\
\hline
\end{tabular}


Figure 1

Overall survival (OS) and Cancer-specific survival (CSS) curves plotted by Kaplan-Meier method for patients received RAI therapy or not.
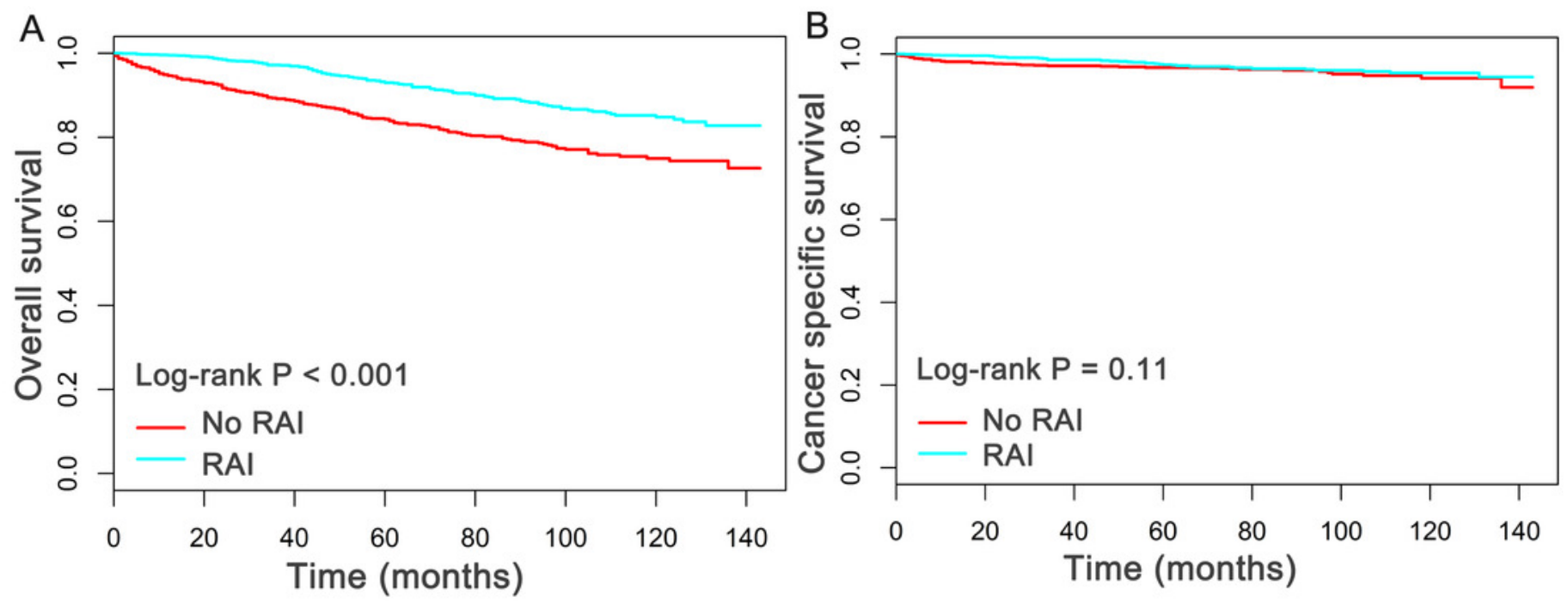
Figure 2

Nomograms for (A) OS and (B) CSS.

Nomogram predicting 3- to 10-year survival probability using eight available clinical characteristics.

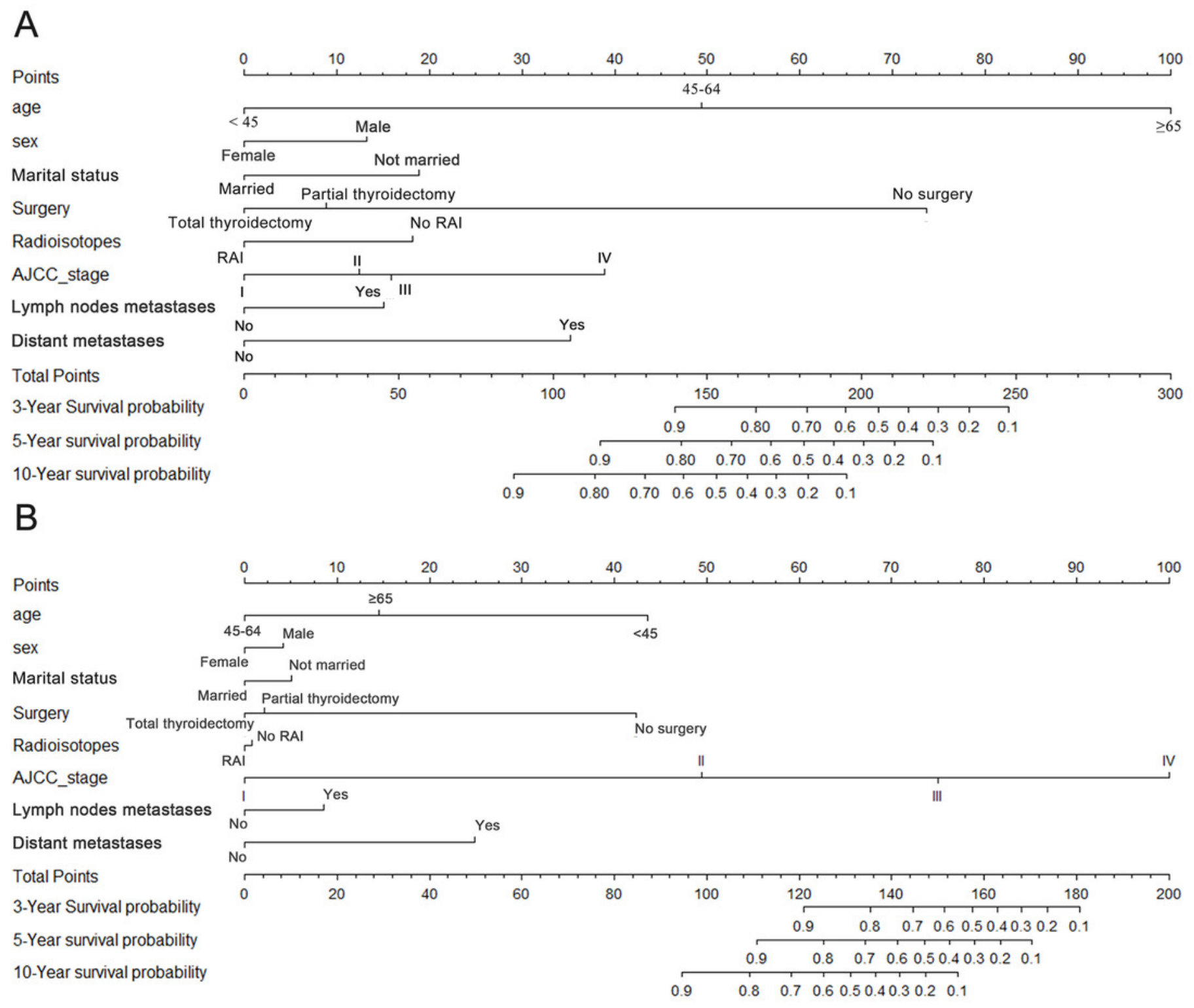


Figure 3

Overall survival (OS) and Cancer-specific survival (CSS) curves plotted by Kaplan-Meier method for I stage $(A, B)$, II stage $(C, D)$, III stage $(E, F)$ and IV stage $(G, H)$ patients. 


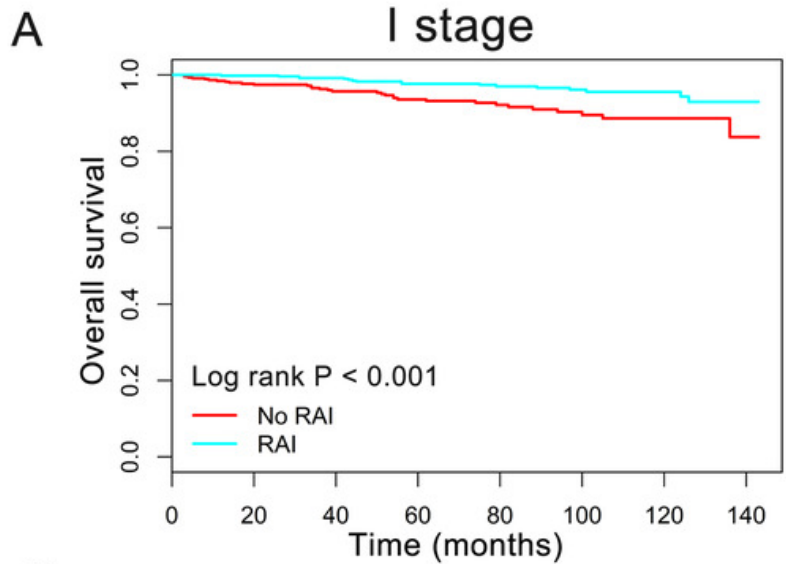

C

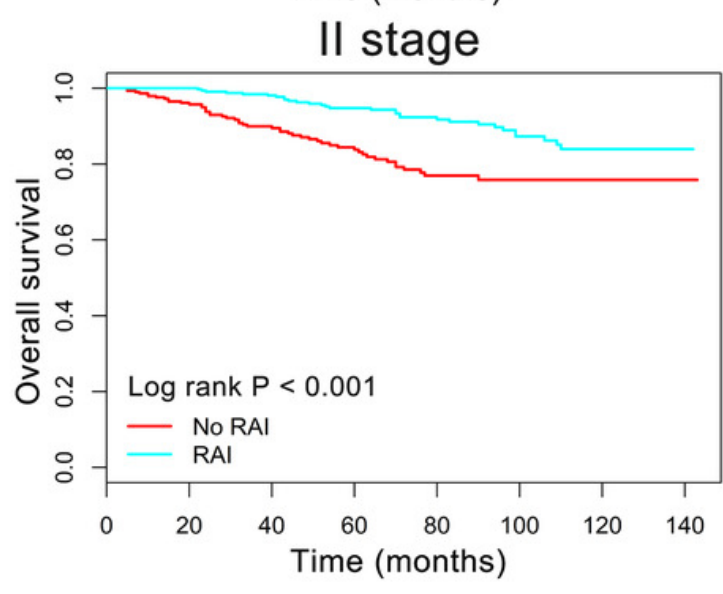

E

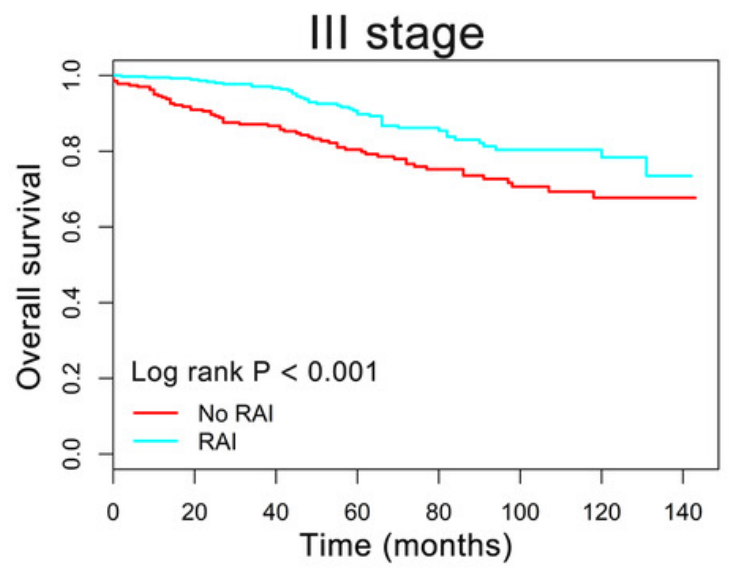

G

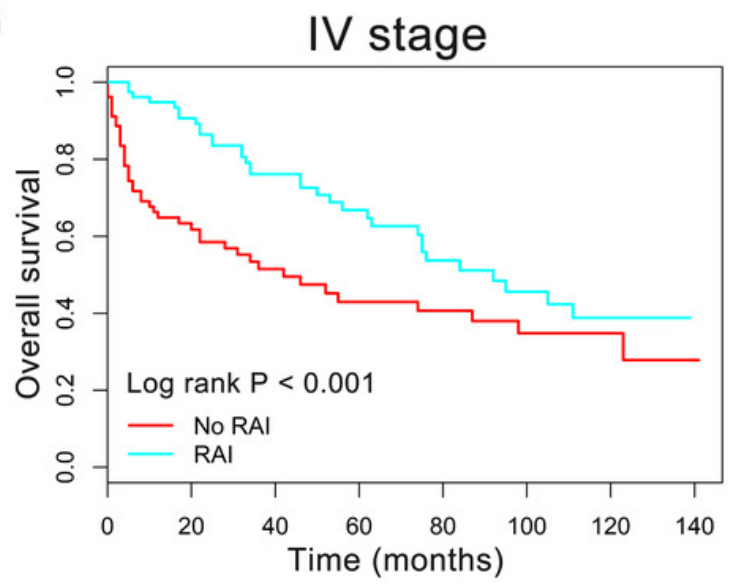

B

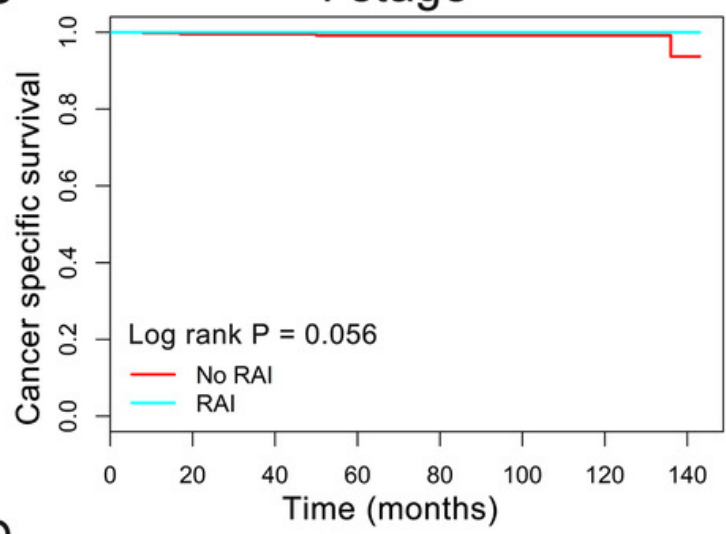

D

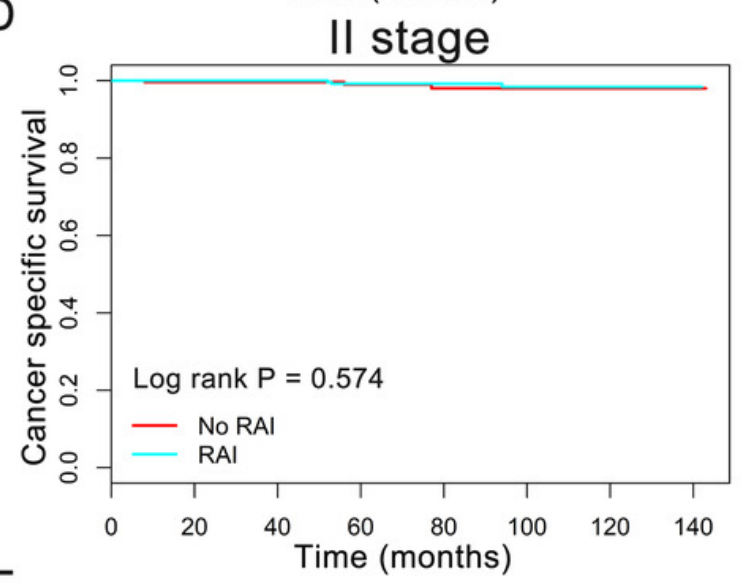

F

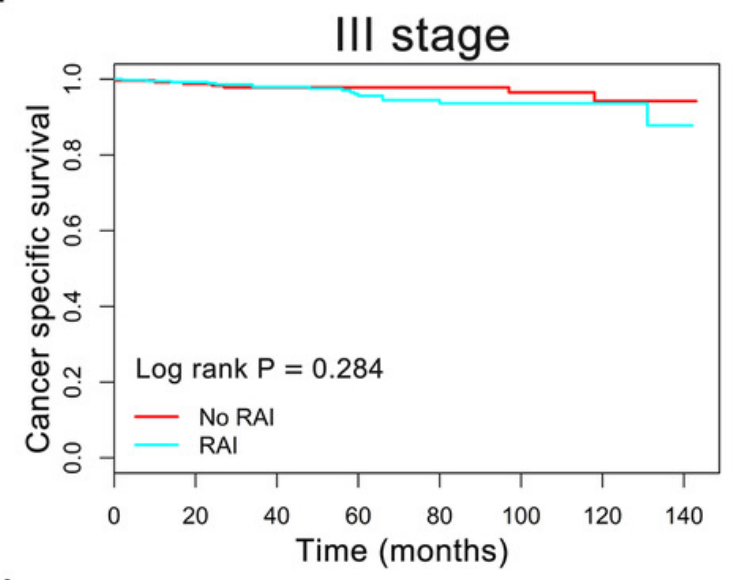

$\mathrm{H}$

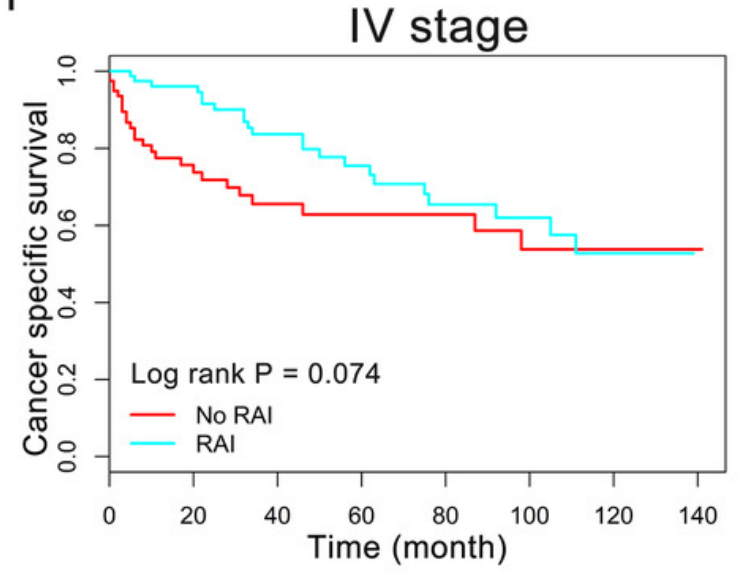


Figure 4

Overall survival (OS) and Cancer-specific survival (CSS) curves plotted by Kaplan-Meier method for patients with or without extrathyroidal invasion.

$\mathrm{HCC}$ confined to the thyroid gland $(\mathrm{A}, \mathrm{B})$ and $\mathrm{HCC}$ with extrathyroidal invasion $(\mathrm{C}, \mathrm{D})$.
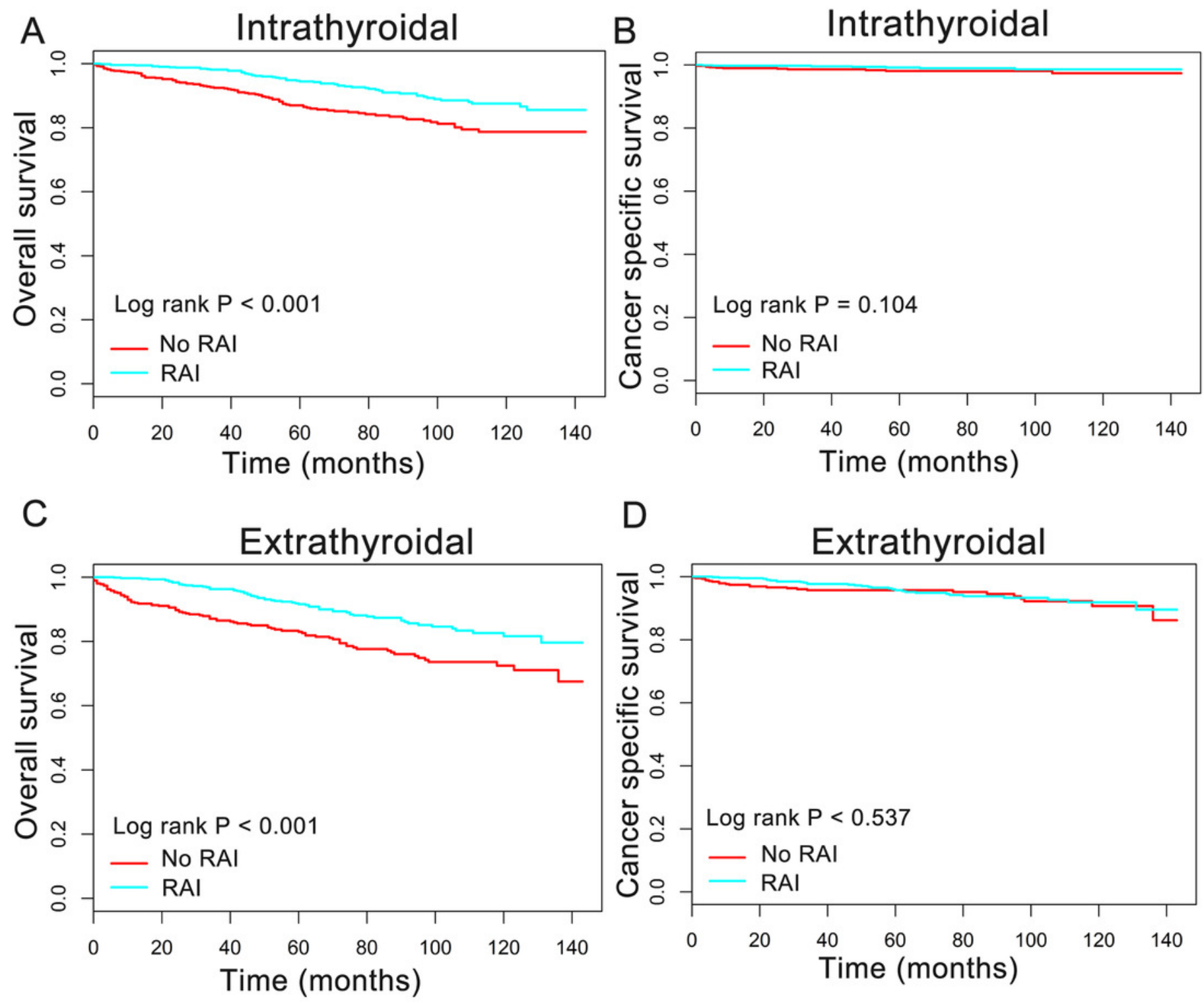
Figure 5

Overall survival (OS) and Cancer-specific survival (CSS) curves plotted by Kaplan-Meier method for NO (A, B) and N1 (C, D) population among HCC patients.

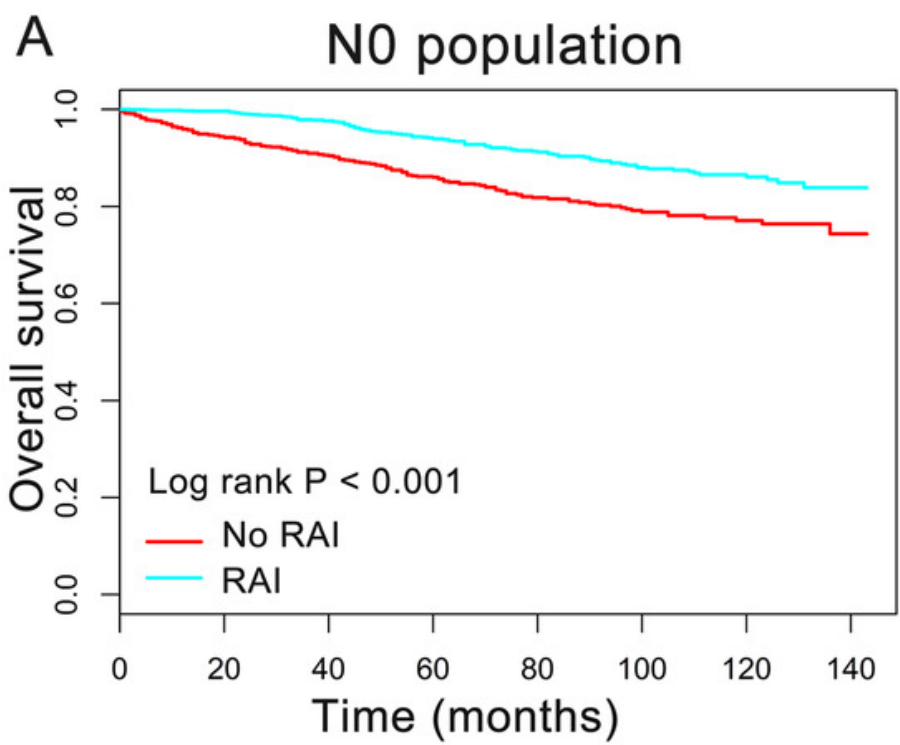

B No population
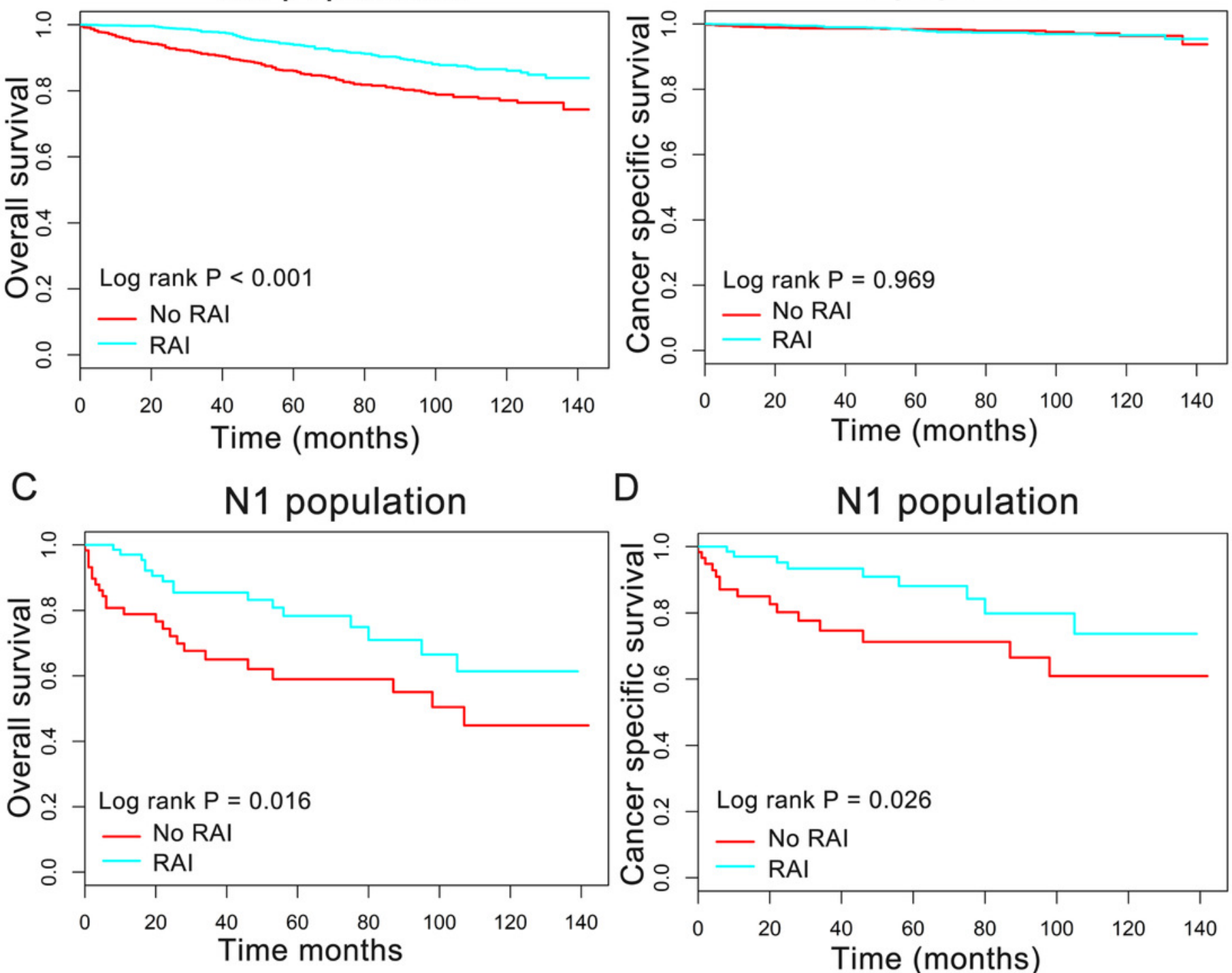

D

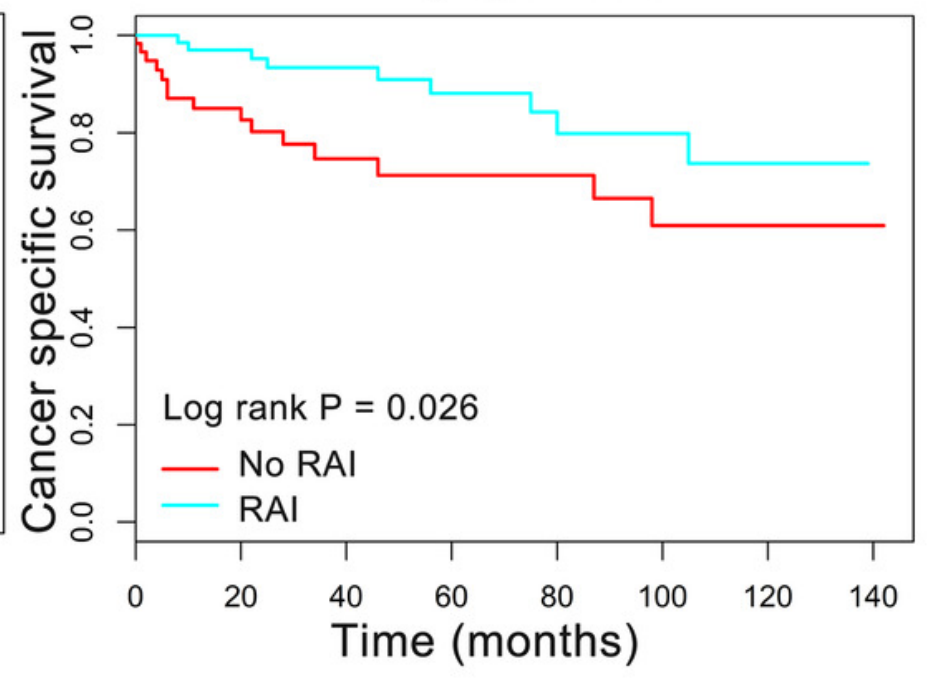

